\title{
Front Matter: Volume 10343
}

, "Front Matter: Volume 10343," Proc. SPIE 10343, Metamaterials, Metadevices, and Metasystems 2017, 1034301 (12 September 2017); doi: $10.1117 / 12.2286366$

SPIE Event: SPIE Nanoscience + Engineering, 2017, San Diego, California, United SPIE. States 


\title{
PROCEEDINGS OF SPIE
}

\section{Metamaterials, Metadevices, and Metasystems 2017}

\author{
Nader Engheta \\ Mikhail A. Noginov \\ Nikolay I. Zheludev \\ Editors
}

6-10 August 2017

San Diego, California, United States

Sponsored and Published by

SPIE 
The papers in this volume were part of the technical conference cited on the cover and title page. Papers were selected and subject to review by the editors and conference program committee. Some conference presentations may not be available for publication. Additional papers and presentation recordings may be available online in the SPIE Digital Library at SPIEDigitalLibrary.org.

The papers reflect the work and thoughts of the authors and are published herein as submitted. The publisher is not responsible for the validity of the information or for any outcomes resulting from reliance thereon.

Please use the following format to cite material from these proceedings:

Author(s), "Title of Paper," in Metamaterials, Metadevices, and Metasystems 2017, edited by Nader Engheta, Mikhail A. Noginov, Nikolay I. Zheludev, Proceedings of SPIE Vol. 10343 (SPIE, Bellingham, WA, 2017) Seven-digit Article CID Number.

ISSN: 0277-786X

ISSN: 1996-756X (electronic)

ISBN: 9781510611436

ISBN: 9781510611443 (electronic)

Published by

SPIE

P.O. Box 10, Bellingham, Washington 98227-0010 USA

Telephone +1 3606763290 (Pacific Time) · Fax +1 3606471445

SPIE.org

Copyright @ 2017 , Society of Photo-Optical Instrumentation Engineers.

Copying of material in this book for internal or personal use, or for the internal or personal use of specific clients, beyond the fair use provisions granted by the U.S. Copyright Law is authorized by SPIE subject to payment of copying fees. The Transactional Reporting Service base fee for this volume is $\$ 18.00$ per article (or portion thereof), which should be paid directly to the Copyright Clearance Center (CCC), 222 Rosewood Drive, Danvers, MA 01923. Payment may also be made electronically through CCC Online at copyright.com. Other copying for republication, resale, advertising or promotion, or any form of systematic or multiple reproduction of any material in this book is prohibited except with permission in writing from the publisher. The CCC fee code is 0277 $786 \times / 17 / \$ 18.00$.

Printed in the United States of America.

Publication of record for individual papers is online in the SPIE Digital Library.

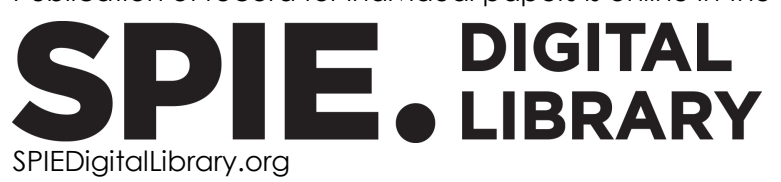

Paper Numbering: Proceedings of SPIE follow an e-First publication model. A unique citation identifier (CID) number is assigned to each article at the time of publication. Utilization of CIDs allows articles to be fully citable as soon as they are published online, and connects the same identifier to all online and print versions of the publication. SPIE uses a seven-digit CID article numbering system structured as follows:

- The first five digits correspond to the SPIE volume number.

- The last two digits indicate publication order within the volume using a Base 36 numbering system employing both numerals and letters. These two-number sets start with $00,01,02,03$, 04, 05, 06, 07, 08, 09, 0A, OB ... 0Z, followed by 10-1Z, 20-2Z, etc. The CID Number appears on each page of the manuscript. 


\section{Contents}

$\checkmark$ Authors

vii Conference Committee

NOVEL CONCEPTS I

1034304 High order plasmonic resonances in time-varying media (Invited Paper) [10343-3]

NOVEL CONCEPTS II

10343 OB Experimental validation of tunable features in laser-induced plasma resonators [10343-10]

\section{ALL-DIELECTRIC METAMATERIALS I}

10343 OF High-Q resonances with low azimuthal indices in all-dielectric high-index nanoparticles [10343-14]

10343 OG Metasurface axicon lens design at visible wavelengths [10343-15]

ACTIVE AND TUNABLE METAMATERIALS

10343 OT Harnessing the metal-insulator transition for tunable metamaterials (Invited Paper)

[10343-28]

METADEVICES AND METASYSTEMS II

1034313 Optoelectronic metasurfaces (Invited Paper) [10343-37]

CHIRALITY AND VORTEXES II

$10343 \mathrm{iN}$ Multiplexing of adjacent vortex modes with the forked grating coupler [10343-57]

METADEVICES AND METASYSTEMS III

1034320 Isotropic metamaterial perfect light absorber using 3D split ring resonator in the mid IR region [10343-70] 
NOVEL CONCEPTS III

1034323 Surface-assisted plasmon decay in metal nanostructures [10343-73]

1034326 Electric field distribution on surface of the artificial magnetic conductor: miniaturization process [10343-76]

\section{QUANTUM METAMATERIALS AND CONCEPTS}

$103432 \mathrm{E} \quad$ Lasing in small-sized aluminum nanoparticle arrays [10343-86]

POSTER SESSION

$103432 \mathrm{H} \quad$ Tunable plasmon induced transparency in a graphene-based waveguide structure and it's applications in sensing [10343-88]

$103432 \mathrm{~L} \quad \mathrm{LiTaO}_{3}$ microcubes based metamaterial perfect absorber [10343-92]

$103432 \mathrm{M} \quad$ Ultrabroadband polarization-independent absorber based on hyperbolic metamaterial [10343-93]

1034320 Automated design of infrared digital metamaterials by genetic algorithm [10343-95]

$103432 R \quad$ Guided modes analysis in metamaterial bounded optical waveguides [10343-98]

$103432 \mathrm{~V}$ Optically tunable Fano-resonant filter based on graphene [10343-102]

$103432 \mathrm{~W}$ A numerical investigation of difference frequency generation in nonlinear multilayered metamaterials [10343-103]

1034332 Design and analysis of tip slotted square patch nano-antenna [10343-109]

1034333 A hybrid phononic waveguide using multilayer structure at mid-infrared [10343-1 10]

1034337 Mass production compatible fabrication techniques of single-crystalline silver metamaterials and plasmonics devices [10343-115]

1034338 Polarizing properties of chiral metasurface based on gammadion crosses with different geometry in THz frequency range [10343-116]

1034339 Anomalous refraction of infrared waves through ultrathin all dielectric metasurfaces [10343-118] 


\section{Authors}

Numbers in the index correspond to the last two digits of the seven-digit citation identifier (CID) article numbering system used in Proceedings of SPIE. The first five digits reflect the volume number. Base 36 numbering is employed for the last two digits and indicates the order of articles within the volume. Numbers start with 00, 01, 02, 03, 04, 05, 06, 07, 08, 09, 0A, 0B...0Z, followed by 10-1Z, 20-2Z, etc.

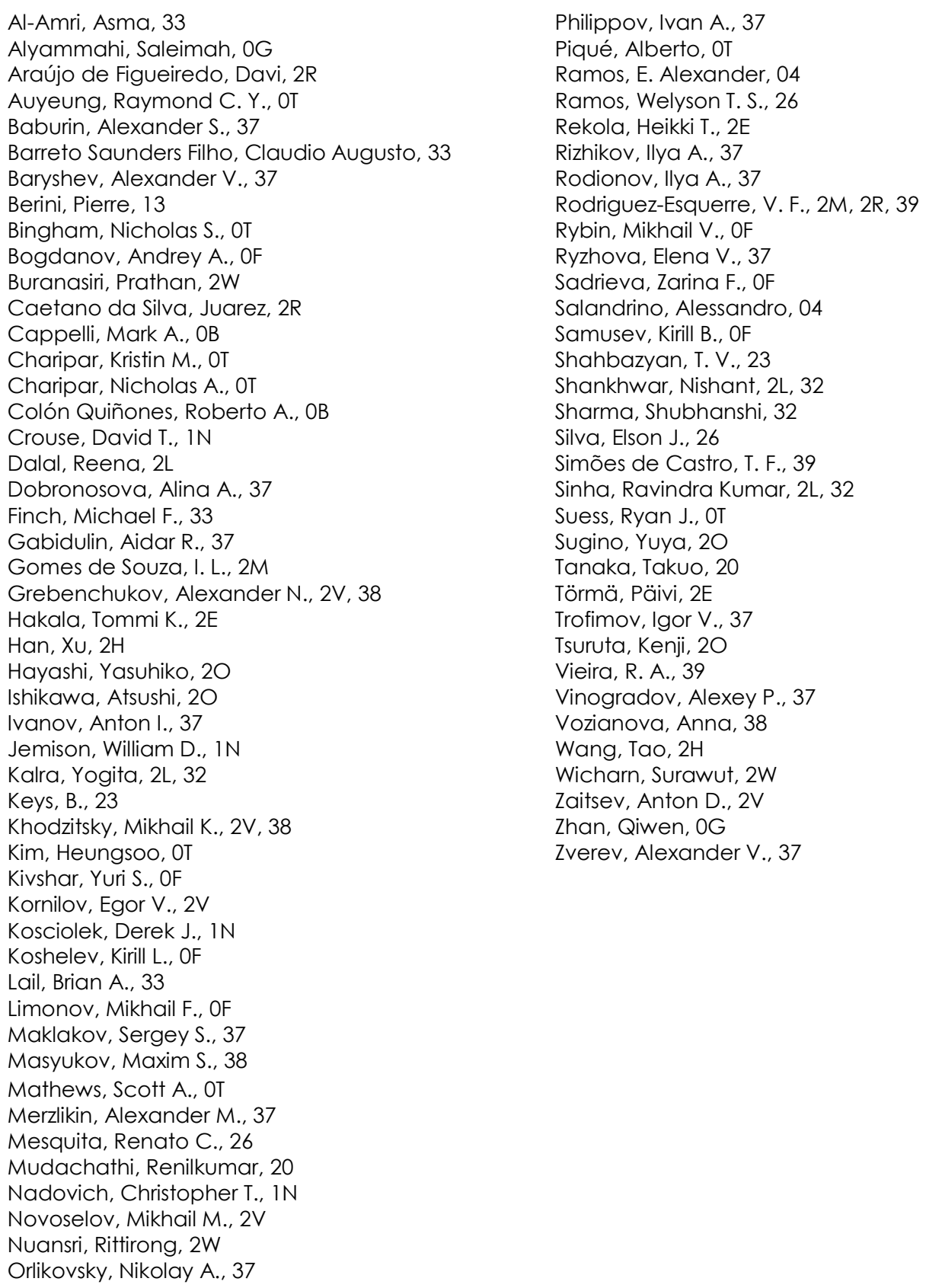

Philippov, Ivan A., 37

Piqué, Alberto, OT

Ramos, E. Alexander, 04

Ramos, Welyson T. S., 26

Rekola, Heikki T., 2E

Rizhikov, llya A., 37

Rodionov, llya A., 37

Rodriguez-Esquerre, V. F., 2M, 2R, 39

Rybin, Mikhail $\mathrm{V}$., OF

Ryzhova, Elena V., 37

Sadrieva, Zarina F., OF

Salandrino, Alessandro, 04

Samusev, Kirill B., OF

Shahbazyan, T. V., 23

Shankhwar, Nishant, 2L, 32

Sharma, Shubhanshi, 32

Silva, Elson J., 26

Simões de Castro, T. F., 39

Sinha, Ravindra Kumar, 2L, 32

Suess, Ryan J., OT

Sugino, Yuya, 20

Tanaka, Takuo, 20

Törmä, Päivi, 2E

Trofimov, Igor $V_{\text {., }} 37$

Tsuruta, Kenji, 20

Vieira, R. A., 39

Vinogradov, Alexey P., 37

Vozianova, Anna, 38

Wang, Tao, $2 \mathrm{H}$

Wicharn, Surawut, $2 \mathrm{~W}$

Zaitsev, Anton D., 2V

Zhan, Qiwen, OG

Zverev, Alexander V., 37 
Proc. of SPIE Vol. 10343 1034301-6

Downloaded From: https://www.spiedigitallibrary.org/conference-proceedings-of-spie on 25 Apr 2023 Terms of Use: https://www.spiedigitallibrary.org/terms-of-use 


\section{Conference Committee}

Symposium Chairs

Harry A. Atwater Jr., California Institute of Technology (United States)

Nikolay I. Zheludev, Optoelectronics Research Centre

(United Kingdom) and Nanyang Technological University

(Singapore)

Symposium Co-chairs

James G. Grote, Air Force Research Laboratory (United States)

David L. Andrews, University of East Anglia (United Kingdom)

Conference Chairs

Nader Engheta, University of Pennsylvania (United States)

Mikhail A. Noginov, Norfolk State University (United States)

Nikolay I. Zheludev, Optoelectronics Research Centre

(United Kingdom) and Nanyang Technological University

(Singapore)

Conference Program Committee

Andrea Alù, The University of Texas at Austin (United States)

David L. Andrews, University of East Anglia (United Kingdom)

Pierre Berini, University of Ottawa (Canada)

Alexandra Boltasseva, Purdue University (United States)

Igal Brener, Sandia National Laboratories (United States)

Mark Brongersma, Standford University (United States)

Joshua D. Caldwell, U.S. Naval Research Laboratory (United States)

Che Ting Chan, Hong Kong University of Science and Technology

(Hong Kong, China)

Luca Dal Negro, Boston University (United States)

Javier García de Abajo, ICFO - Institut de Ciències Fotòniques (Spain)

Harald W. Giessen, Universität Stuttgart (Germany)

Richard Hammond, U.S. Army Research Office (United States)

Yuri S. Kivshar, The Australian National University (Australia)

Jacob B. Khurgin, Johns Hopkins University (United States)

Uriel Levy, The Hebrew University of Jerusalem (Israel)

Natalia M. Litchinitser, University at Buffalo (United States)

Martin W. McCall, Imperial College London (United Kingdom)

Peter Nordlander, Rice University (United States)

Alberto Piqué, U.S. Naval Research Laboratory (United States) 
Alessandro Salandrino, The University of Kansas (United States)

Gennady B. Shvets, The University of Texas at Austin (United States)

David R. Smith, Duke University (United States)

Mark I. Stockman, Georgia State University (United States)

Philippe Tassin, Chalmers University of Technology (Sweden)

Päivi Törmä, Aalto University School of Science (Finland)

Sergei Tretyakov, Aalto University School of Science and Technology (Finland)

Din Ping Tsai, National Taiwan University (Taiwan)

Augustine M. Urbas, Air Force Research Laboratory (United States)

Martin Wegener, Karlsruher Institut für Technologie (Germany)

Jeong Weon Wu, Ewha Womans University (Korea, Republic of)

Xiang Zhang, University of California, Berkeley (United States)

\section{Session Chairs}

1 Novel Concepts I

Alexander B. Khanikaev, The City College of New York (United States)

2 Novel Concepts II

Isabelle Staude, Friedrich-Schiller- Universität Jena (Germany)

3 All-Dielectric Metamaterials I

Zubin Jacob, Purdue University (United States)

4 All-Dielectric Metamaterials II

Philippe Tassin, Chalmers University of Technology (Sweden)

$5 \quad$ Strong Coupling

Adam Dunkelberger, U.S. Naval Research Laboratory (United States)

6 Active and Tunable Metamaterials

Blake S. Simpkins, U.S. Naval Research Laboratory (United States)

7 Metadevices and Metasystems I

Augustine M. Urbas, Air Force Research Laboratory (United States)

8 Metadevices and Metasystems II

Andrey Karlovich Sarychev, Institute for Theoretical and Applied Electrodynamics (Russian Federation)

9 Nonlinear Metamaterials

Martin F. Schumann, Karlsruher Institut für Technologie (Germany)

10 Metasurfaces

Anders Kristensen, DTU Nanotech (Denmark) 
11 Chirality and Vortexes I

Cesare Soci, Nanyang Technological University (Singapore)

12 Chirality and Vortexes II

Vera N. Smolyaninova, Towson University (United States)

13 Hyperbolic Metamaterials

Natalia M. Litchinitser, University at Buffalo (United States)

14 Metadevices and Metasystems III

Mark Lawrence, Stanford University (United States)

15 Novel Concepts III

Meir Orenstein, Technion-Israel Institute of Technology (Israel)

16 2D Metamaterials

Viktor A. Podolskiy, University of Massachusetts Lowell (United States)

17 Quantum Metamaterials and Concepts

Ertugrul Cubukcu, University of California, San Diego (United States) 
Proc. of SPIE Vol. 10343 1034301-10 Downloaded From: https://www.spiedigitallibrary.org/conference-proceedings-of-spie on 25 Apr 2023
Terms of Use: https://www.spiedigitallibrary.org/terms-of-use 